\title{
Bionics vs. biomimicry: from control of nature to sustainable participation in nature
}

\author{
D. C. Wahl \\ Centre for the Study of Natural Design, University of Dundee, UK
}

\begin{abstract}
Quantum theory, complexity theory, and ecosystems theory, along with anthropogenic climate change and ecosystem collapses are confronting humanity with insights that will crucially inform the re-design of products, processes, services and institutions in order to catalyse the transition towards a sustainable human civilization. In a fundamentally interconnected and unpredictable world, where local actions have global consequences, the intentionality behind science and design needs to shift from aiming to increase prediction, control and manipulation of nature as a resource, to a transdisciplinary cooperation in the process of learning how to participate appropriately and sustainably in Nature.

A participatory conception of nature-culture relationships acknowledges the dependence of humanity on healthy ecosystems and a healthy biosphere. It implies the need for a salutogenic design approach that increases human, societal and ecological health synergistically. In order to create sustainable designs that are sensitive to the unique social, cultural and ecological conditions of a particular place and facilitate the emergence of health as a system-wide and scale linking property, designers will have to move from a detached perspective of culture as apart from nature and learning about nature, to a more holistic and participatory perspective of culture as a part of Nature and learning from Nature.

This paper suggests that bionics and biomimicry represent two distinct approaches to 'design and nature' based on different conceptions of the relationship between nature and culture. An effective transition towards sustainability, mediated by design, will have to be informed by a holistic and participatory conception of nature and culture within a fundamentally interconnected and unpredictable complex dynamic system.

Keywords: sustainability, complexity, bionics, biomimicry, transdisciplinary, design, health, scale-linking, salutogenic, ecology.
\end{abstract}




\section{Introduction}

Five hundred years ago Leonardo da Vinci [1] warned: "Those who take for their standard any one but nature - the mistress of all masters - weary themselves in vain" (p.xxx). Did da Vinci foresee that the Scientific Revolution would set humanity on a path predominantly driven by the aim to increase our ability to predict, control, and manipulate nature, rather than to learn from and integrate into nature?

Galileo Galilee called for a focus on the measurable, quantitative aspects of nature and regarded qualitative aspects to be of secondary importance. Francis Bacon described the vision of humanity as 'master of nature.' Rene Descartes created the conceptual separation of mind and body, humanity and nature, and subject and object into dualistic, mutually exclusive categories; he also offered the mechanistic clockwork metaphor. Together, they created the basis for a reductionistic science of detached objectivism.

This approach to science separated human beings, as objective observers, from their biological nature as participants in a fundamentally interconnected natural process. The root cause of the utter unsustainability of modern civilization lies in the dualistic separation of nature and culture. It is in nature, that all peoples and all species unite into a community of life. Yet culture is commonly conceived of as apart from nature, rather than a part of nature. Since the Industrial Revolution, reductionist science has enabled us to design a whole host of powerfully manipulative technologies, which have transformed the planet.

These technological inventions have undeniably improved the standard of living of many people, but for centuries, the hidden connections [2] linking human activities to ecosystems and the biosphere, have been ignored. Many modern technologies of comfort (e.g. jet travel, the use of internal combustion engines, air conditioning, industrialized agriculture and food systems) are actually creating more problems than benefits, when such designs are considered in an ecological and planetary context. Their effects on the quality of life of this and future generations will not be beneficial in the long-term.

The unbridled use of fossil fuels and other natural resources along with the unrestrained disruption of ecosystems have, within only two centuries, altered the planet's atmospheric composition and climate patterns [3] and decreased the resilience [4] and health of many of the world's ecosystems [5].

The avant-garde sciences, represented by quantum physics [6], cognitive biology and consciousness studies [7], chaos theory [8], ecosystem science [9], human ecology [10], and the theory of complex dynamic systems [11], have long moved beyond the anachronistic paradigm of prediction and control of nature. These sciences acknowledge that we are living in a complex, interconnected, constantly changing, and - beyond a very limited spatial and temporal scale fundamentally unpredictable and uncontrollable world. Local actions can have far-reaching global consequences. Cause and effect relationships in complex dynamic systems are non-linear, multi-causal, and often time-delayed and spatially removed [12]. 
Modern science has begun to transcend and include the detached, quantitative and reductionist approach of Cartesian science and now seeks to integrate it into a more participatory, qualitative and holistic conception of humanity's relationship to the natural world. The aim of science is shifting towards informing appropriate participation in natural process, rather than the enabling of new technologies of prediction, manipulation and control [13].

The transition towards sustainability will require a new approach to design and technology that is based on a participatory and holistic worldview informed by science, ethics and the transdisciplinary integration of multiple perspectives [14]. It is a biophysical and ecological fact that culture is never truly separate from nature. Quality of life and the spectrum of consciousness have a psychological, spiritual, inner dimension that cannot be described solely scientifically.

All human design and technology interacts with the natural cycles that maintain the health of ecosystems and the planetary life-support system. Humanity depends on ecosystems services for its survival [15]. Sustainability depends on healthy individuals in healthy communities and societies $[15,17]$ just as much as these depend on healthy ecosystems and planetary health [18-20].

Hawken [21] identified design as an integrative concept for the prevention of environmental damage. Design also implies a need for decision-making based on multiple perspectives and disciplines. When design is informed by ecological literacy [22] it offers an integrative framework for meeting human needs within the limits set by natural process at a local, regional and global scale [23-26].

Orr [27] describes ecological design as "a large concept that joins science and the practical arts with ethics, politics and economics" (p.4) and emphasizes that such a design approach "is not so much about how to make things as about how to make things that fit gracefully over long periods of time in a particular ecological, social, and cultural context" (p.27). David Orr writes: "The problem is simply how a species pleased to call itself Homo sapiens fits on a planet with a biosphere. This is a design problem and requires a design philosophy. The very idea that we need to build a sustainable civilization needs to be invented or rediscovered, then widely disseminated, and put into practice quickly" (p.50).

\section{Learning from nature as model, measure, and mentor}

In the 1960s and 70s, McHarg [28] and the founders of the 'New Alchemy Institute' - Todd, Jack-Todd and McLarney [29] - were among the pioneers of a new approach to design, aiming to integrate into natural process and apply nature's design lessons to the creation of more sustainable human infrastructures, products and processes.

John Todd [30] describes his vision for design in the $21^{\text {st }}$ century: "The Earth's ecologies are embedded with a set of instructions that we urgently need to decode and employ in the design of human systems" (p.1). After forty years of research at the nexus of biology, ecology and design, Todd emphasizes: "it is possible to design with Nature ... through ecological design, it is possible to 
have a high civilization using only one tenth of the world's resources that industrial society uses today" (p.3).

\subsection{Bionics: A prediction and control approach to learning from nature}

In parallel with the emergence of ecological design and its strategy of biomimicry, a more technologically oriented approach to applying nature's design lessons has also evolved since the 1960s, when the US Air Force engineer, Major J.E. Steele coined the term 'bionics.' While it has, at points, been predominantly identified with the creation of artificial human body parts bionic ears, limbs, and eyes [31], the field of bionics is currently gaining in scope and popularity.

Since the 1970s, particularly through the pioneering work of the German zoologist Werner Nachtigall, bionics has developed into an increasingly influential support discipline for engineers and technologists. According to Nachtigall [32] bionics is the process of "learning from nature as an inspiration for independent technical design" (p.1). Nachtigall formulated a series of principles of bionic design, a translation of which is provided in table 1 .

Table 1: $\quad$ Principles of bionic design.

1. Integrated instead of additive construction

2. Optimisation of the whole, rather than maximization of individual elements

3. Multifunctionality instead of monofunctionality

4. Fine-tuning adapted to particular environments

5. Energy saving instead of energy squandering

6. Direct and indirect use of solar energy

7. Temporal limitation instead of unnecessary durability

8. Total recycling instead of waste accumulation

9. Networks instead of linearity

10. Development through the process of trial and error

Source: Nachtigall [32], pp.21-34

As a scientific discipline, bionics takes a systems approach to the technical realization and application of construction processes and developmental principles observed in biological systems. It has contributed to technological innovations in aero- and fluid-dynamics, echolocation and sonar, lightweight construction, ventilation, packaging, adhesion, propulsion, pumping, locomotion, material composition, volume optimisation and other fields [32]. However, the technical rigor and engineering mindset of bionics has merits and limitations.

Germany is currently taking a leading role in the field of bionics research. There is a 'Society for Technical Biology and Bionics', as well as an established 'Bionics Competency Network.' The University of the Applied Sciences in Bremen offers the first 'BSc. in Bionics', and organized a conference in 
November 2004, which united a vibrant community of researchers. Unfortunately the focus was so exclusively on technological innovation that it almost actively tried to discourage ecological concerns and the issue of sustainability.

Without acknowledging the complex context of sustainability and ecological and social interactions, bionics, planning, design, engineering, and resource management, all run the risk of staying trapped in a prediction and control mindset. This will ultimately perpetuate unsustainable practices, as it ignores the complex interplay of diverse social, cultural, economic and ecological factors that have to be brought into synergy in order to create sustainable solutions and design.

\subsection{Biomimicry: ecologically informed design for sustainability}

The first researchers to offer a list of principles for ecologically or biologically informed design were John Todd and his wife Nancy Jack-Todd [24, 33]. During the 1970s, research at the 'New Alchemy Institute' began to explore how ecology, biology, and a bio-cybernetic systems approach, could inform more sustainable solutions to meeting fundamental human needs. Table 2, below reproduces the initially proposed nine precepts, augmented by a tenth precept that was added more recently [34] to stress the centrality of design as an expression of intentionality in all human interactions and relationships.

Table 2: $\quad$ Precepts of biological design.

1. The living world is the matrix for all design.

2. Design should follow, not oppose the laws of life.

3. Biological equity must determine design.

4. Design must reflect bioregionality.

5. Projects should be based on renewable energy sources.

6. Design should be sustainable through the integration of living systems.

7. Design should be co-evolutionary with the natural world.

8. Building and design should help heal the planet.

9. Design should follow a sacred ecology.

10. Everyone is a designer!

Source: Jack-Todd \& Todd, [33] p.19-79, [34]

This list of biological design precepts clearly reflects the holistic and participatory worldview that informs integrated sustainable design. The diverse and transdisciplinary movement that has grown out of this participatory, and ethically responsible approach to ecological design has been described as the 'Bioneers' [35, 36], as natural design [37], or the natural design movement [38].

After investigating a wide range of research initiatives aimed at creating new and more sustainable technologies, materials, and products based on insights 
gained through the detailed investigation of biological and ecological processes, Janine Benyus [39] documented and integrated her findings in Biomimicry Innovation Inspired by Nature. Her definition of the biomimicry approach is reproduced in table 3 , below.

Table 3: $\quad$ The biomimicry approach.

1. Nature as model. Biomimicry is a new science that studies nature's models and then imitates or takes inspiration from these designs and processes to solve human problems.

2. Nature as a measure. Biomimicry uses an ecological standard to judge the "rightness" of our innovations. After 3.8 billon years of evolution, nature has learned: What works. What is appropriate. What lasts.

3. Nature as a mentor. Biomimicry is a new way of viewing and valuing nature. It introduces an era based not on what we can extract from the natural world, but on what we can learn from it.

Source: Benyus, [40] p.iii

Johnson and Hill [40] recently edited an informative compendium on how ecological insights can profoundly shape the way we design. They argue: "To ignore [the] reciprocal relationship of human culture and ecosystems is to turn away from a fundamental reality of the landscapes we share with other people and other species" and suggest: "As a basic principle for collaboration among design disciplines and the new fields of applied ecology, we propose that all landscape design, planning, and management should be evaluated through a thorough accounting of its consequences for ecological health, biotic integrity, and cultural well-being - human, social, and economic" (p.12).

\section{Sustainability: the 'wicked problem' of design}

First Horst Rittel and later Richard Buchanan [41] described design problems that involve complex, interrelated issues and diverse stakeholders, and are fuzzy and ill defined as 'wicked problems.' Recently, Wahl [38] suggests that sustainability is the wicked problem of design in the $21^{\text {st }}$ century. From now on, all problem solving, decision and policy-making, and all aspects of design have to consider their impact on the health of individuals, communities, societies, ecosystems and the planetary life-support system in order to be sustainable.

Sustainable solutions require transdisciplinary integration of multiple knowledge bases. Design can play the role of integrator and facilitator in this process [14]. The complexity of the interrelated social, economic, cultural and ecological problems that are facing humanity not only call for collaboration between diverse disciplines but also for political and civic cooperation on a local, regional, national, and global scale. The creation of a sustainable civilization is a design challenge of unprecedented magnitude and generational importance. 
Battram [42] explains: "Complex adaptive systems are constantly revising and rearranging their components in response to feedback from the environment" (p.36). He emphasizes that such systems are continuously changing and transforming. Participating agents are never able to optimise their fitness or utility, since there are too many possibilities.

Vester [12] points out: "Since complex systems require a constant dynamism in the way we think about them and therefore a heuristic structure" our approach to problem-solving has "to include the entire range of ways in which humans can reach insights" (p.38). Vester describes a study by the German systemspsychologist Dietrich Dörner that investigated the way transdisciplinary teams engage in the process of solving complex, unpredictable and interrelated problems. Table 4 lists six common mistakes in dealing with complex systems.

Table 4: Common mistakes in dealing with complex systems.

1. Inadequate definition of goals (vision)

2. Lack of a joined-up systems analysis

3. The creation of irreversible emphasis

4. Lack of attention to side-effects

5. The tendency to over-steer or over-react

6. The tendency to act in an authoritarian (controlling) way

Source: after D. Dörner, in Vester, [12], pp.36-37

The complex dynamic systems that join nature and culture into a mutually dependent whole require us to create flexible and adaptable solutions that can respond to dynamic system changes. Nature constantly changes! Anthropogenic climate change and ecosystem degradation only accelerate systemic change. Sustainability is not an achievable steady state! Rather, it is a continuous process of community-based learning of how to participate appropriately in natural process.

Design for sustainability is materially expressed through sustainable products and infrastructures, but more profoundly, through sustainable communities, lifestyles, and societies. Increasing sustainability is about creating flexible and dynamically networked structures of self-sustaining, autopoietic [7] wholes within wholes. This requires the creation and empowerment of sustainable communities of responsible, eco-literate citizens adapted to the challenges and opportunities of a particular, local ecology and culture [22,27], cooperatively linked into mutual support networks that span from local to regional to global scale [38].

Such design requires sensitivity to the various scales of ecological design as proposed by Janis Birkeland [43]: product design, eco-architecture, construction ecology, community design, industrial ecology, urban ecology, and bioregional planning. The restoration of ecological and cultural health and well-being requires scale sensitive design - the creation of healthy, resilient, flexible and adaptive 'holarchies' [38], 'holonocracies' [19], or 'panarchies' [4]. The future 
is unpredictable and uncertain. Adaptive complex dynamic networks are nature's way of responding effectively to change. Sustainable design that reintegrates culture and nature has to emulate nature's way of dealing with unpredictability, fundamental interconnectedness and dynamic transformation.

Nature is fundamentally scale linking. Events at the molecular scale of photosynthesis and digestion affect the bio-productivity of ecosystems, as well as atmospheric composition and climate patterns. Design has to integrate into natural processes at the appropriate scale [23-26]. In general, sustainable design has to be scale linking, synergistic, symbiotic, sacred and salutogenic (healthpromoting) [38]. These are nature's lessons for natural design!

\section{Conclusion}

It is of limited use to draw a sharp line between the approaches of bionics and biomimicry, based on the relative importance these approaches give to achieving greater sustainability. Much of the British research in biomimetics is done in a bionics mindset of aiming for increased prediction, manipulation and control. Both fields, if they are indeed distinct, can contribute greatly to more sustainable solutions. The intention of this paper is not a discussion of semantic definition, nor the creation of dualistic categories; rather it aims to highlight the crucial role of intentionality in the design of more sustainable products, processes and services. Nature can teach us how to be life sustaining and health promoting.

As the postmodern world is taking shape amidst globalisation, climate change, economic instability, global and local inequality, resource wars and rapid species loss, an ecologically and socially literate worldview is emerging. It not only acknowledges the complex interactions and relationships between social, cultural, economic, and ecological systems, but also integrates multiple perspectives and considers material, ethical, psychological, and spiritual issues.

Most broadly defined, design is the expression of intentionality through interactions and relationships. This intention changes significantly when design is approached from within a perspective of culture as separate from nature and aiming to control and manipulate nature more effectively, or from within a more holistic and eco-literate perspective that regards culture as a co-dependent participant in natural process. Such changes in intention are changes in metadesign that affect all human activity. Changing the intentions behind design changing mind stet - is design at the paradigm level and life style level. The creation of a sustainable civilization is primarily about such fundamental changes in dominant worldviews, value systems, intentions, and life styles.

\section{References}

[1] Schneider, M.S., A Beginner's Guide to Constructing the Universe: The Mathematical Archetypes of Nature, Art, and Science, HarperCollins: New York, 1995

[2] Capra, F., The Hidden Connections: A Science for Sustainable Living, HarperCollins: New York, 2002 
[3] Intergovernmental Panel on Climate Change (IPCC), Climate Change 1995, Cambridge University Press, Cambridge, 1995

[4] Gunderson, L.H. \& Holling, C.S., Panarchy: Understanding Change in Human and Natural Systems, Island Press: Washington D.C., Covelo, London, 2002

[5] Millennium Ecosystem Assessment, Living Beyond Our Means: Natural Assets and Human Well-Being, www.millenniumassessment.org

[6] Capra, F., The Tao of Physics: An Exploration of the Parallels Between Modern Physics and Eastern Mysticism, third edition, Shambhala Publications, Boston, 1991

[7] Maturana, H.R. \& Varela, F.J., The Tree of Knowledge: The Biological Roots of Human Understanding, Shambhala Publications, Boston, 1988

[8] Briggs, J. \& Peat, D.F., Seven Life Lessons of Chaos: Timeless Wisdom from the science of change, HarperCollins, New York, 1999

[9] Botkin, D., Quammen, D., McPhee, J., Gould, S.J., Margulis, L. et al., Forces of Change: A New View of Nature, Smithsonian National Museum of Natural History \& The National Geographic Society, Washington, 2000

[10] Marten, G.G., Human Ecology: Basic Concepts For Sustainable Development, Earthscan Publications: London, Sterling VA, 2001

[11] Goodwin, B.C., How the Leopard Changed its Spots: The Evolution of Complexity, Weidenfeld \& Nicolson: London, 1994

[12] Vester, F., Die Kunst vernetzt zu Denken: Ideen und Werkzeuge für einen neuen Umgang mit Komplexität, Der neue Bericht an den Club of Rome, Deutscher Taschenbuch Verlag: München, 2004

[13] Goodwin, B.C., From Control to Participation via a Science of Qualities. Revision: A Journal of Consciousness \& Transformation, 21(4), pp. 2-10, 1999

[14] Wahl, D.C., Ecoliteracy, Ethics and Aesthetics in Natural Design: The Artificial as an Expression of Natural Process, Design System Evolution, European Academy of Design Conference, Bremen, 2005

[15] Daily, G.C., (ed). Nature's Services: Societal Dependence on Natural Ecosystems, Island Press: Washington, D.C., Covelo, California, 1997

[16] Wilkinson, R.G., Unhealthy Societies: The Afflictions of Inequality, Routledge: London, 1996

[17] Wilkinson, R.G., The Impact of Inequality: How to Make Sick Societies Healthier, Routledge: London, 2005

[18] Todd, J., Human Health/Planetary Healing: A Necessary Unity. Annals of Earth, 21(1), pp. 16-17, 2003

[19] Waltner-Toews, D., Ecosystem Sustainability and Health: A Practical Approach, Cambridge University Press: Cambridge, 2004

[20] Brown, V.A., Grootjans, J., Ritchie, J., Townsend, M. \& Verrinder, G., Sustainability and Health: Supporting Global Ecological Integrity in Public Health, Earthscan Publications: London, 2005

[21] Wann, D., Deep Design: Pathways to a Livable Future, (foreword by Hawken, P.), Island Press: Washington, D.C., Covelo, California, 1996 
[22] Orr, D.W., Ecological Literacy: Education and the Transition to a Postmodern World, State University of New York Press: New York, 1992

[23] McHarg, I.L., Design with Nature, The American Museum of Natural History \& Doubleday: New York, 1969

[24] Jack-Todd, N. \& Todd, J., Bioshelters, Ocean Arks, City Farming: Ecology as the Basis of Design, Sierra Book Club: San Francisco, 1984

[25] Lyle, J.T., Design for Human Ecosystems: Landscape, Land Use, and Natural Resources, Van Nostrand Reinhold Company: New York, 1985

[26] Van der Ryn, S. \& Cowan, S., Ecological Design, Island Press: Washington, D.C., Covelo, California, 1996

[27] Orr, D.W., The Nature of Design: Ecology, Culture, and Human Intention, Oxford University Press: Oxford, 2002

[28] McHarg, I.L. \& Steiner, F.R., To Heal the Earth - Selected Writings of Ian L. McHarg, Island Press: Washington D.C., Covelo, California, 1998

[29] Jack-Todd, N., A Safe and Sustainable World: The Promise of Ecological Design, Island Press: Washington D.C., Covelo, California, 2005

[30] Todd, J., Ecological Design in the $21^{\text {st }}$ Century. Annual Schumacher Lecture, Schumacher Society, Bristol, www.oceanarks.org, pp. 1-3, 2000

[31] Rosaler, M., Science on the Edge: Bionics, Blackbirch Press: USA, 2003

[32] Nachtigall, W., Vorbild Natur: Bionik-Design für funktionelles Gestalten, Springer Verlag: Berlin, Heidelberg, New York, 1997

[33] Jack-Todd, N. \& Todd, J., From Eco-Cities to Living Machines: Principles of Ecological Design, North Atlantic Books: Berkeley, 1993

[34] Todd, J \& Jack-Todd, N., Personal communication, Course in Ecological Design at Schumacher College, Devon, May 2004

[35] Ausubel, K., Restoring the Earth - Visionary Solutions from the Bioneers, HJ Kramer: Tiburon, California, 1997

[36] Ausubel, K., (ed.) Nature's Operating Instructions: The True Biotechnologies, Bioneers Series, Sierra Book Club: San Francisco, 2004

[37] Baxter, S., Deep Design and the Engineers Conscience: A Global Primer for Design Education. Crossing Design Boundaries, eds. P. Rodgers, L. Brodhurst \& D. Hepburn, Taylor \& Francis: London, pp.283-287, 2005

[38] Wahl, D.C., Design for Human and Planetary Health: A Holistic/Integral Approach to Complexity and Sustainability, $\mathrm{PhD}$. thesis submitted at the Centre for the Study of Natural Design, University of Dundee, Scotland

[39] Benyus, J.M., Biomimicry: Innovation Inspired by Nature, $2^{\text {nd }}$ edition, HarperCollins: New York, 2002 (first publ. in 1997)

[40] Johnson, B.R. \& Hill, K., (eds.) Ecology and Design - Frameworks for Learning, Island Press: Washington D.C., Covelo, London, 2002

[41] Buchanan, R., Wicked Problems in Design Thinking. The Idea of Design, eds. V. Margolin \& R. Buchanan, MIT Press: Cambridge, pp. 3-20, 1995

[42] Battram, A., Navigating Complexity - The essential Guide to Complexity theory in Business and Management, Stylus Publishing: Sterling, VA, 1998

[43] Birkeland, J., (ed.) Design for Sustainability: A Sourcebook of Integrated Eco-logical Design, Earthscan Publications: London, 2002 